\title{
POLÍTICAS DE CORPOS: VIDAS FEMININAS NEGRAS
}

\author{
Body politics: Black Female lives
}

Nayara Lima Longo ${ }^{1}$

\section{Resumo}

Este trabalho procura problematizar determinadas políticas de subjetivação ligadas ao corpo que constituem subjetividades femininas negras. O investimento visa disparar elementos que tensionem algumas das hierarquizações identitárias emergentes neste processo, procurando com isto dar passagem à potência de afirmação de cada corpo, na composição de liberdades possíveis.

Palavras-chave: Corpo. Mulher negra. Subjetividade. Minorias.

\begin{abstract}
This work aims to question certain politics of subjectivation related to do body constituting black feminine subjectivities. The project aims on elements that has a stressful effect on some of the creation processes of identity hierarchies emerging during this process. With this all, making space for the power of affirmation of every body, as possible liberties.
\end{abstract}

Key-words: Body. Black woman. Subjectivity. Minorities.

\footnotetext{
${ }^{1}$ [Doutoranda DMMDC (UFBA); Mestra em Psicologia (UFF); Especialista em Conscientização pelo Movimento e Jogos Corporais (FAV); Especialista em Estudos Contemporâneos em Dança (UFBA); Psicóloga (UNESP). E- mail: nayaralongo@yahoo.com.br].
} 


\section{1- O FIO DAS HISTÓRIAS}

Um coletivo que se faz na diferença. Atravessamentos de histórias que simultaneamente coletivizam e singularizam. Vidas.

Nasci em uma pequena cidade do interior de São Paulo: Cravinhos. Este nome deve-se a pequenas flores amarelas que por lá abundam. Há quem diga também que o nome vem de (es)cravinhos - diminutivo da palavra escravos - referindo-se à população que possivelmente trabalhou nestas terras quando da chegada dos posseiros cafeicultores. Entre uma versão e outra, melhor as duas. O lugar tem seu marco oficial inicial, com o desmatamento do lugar promovido pela empreitada voraz de latifundiários plantadores de café vindos de Rezende-RJ, no final do século XIX, na busca da fértil terra roxa. Para tal empreitada, trouxeram consigo a tiracolo um pequeno punhado de braços, pernas, mãos, corpos escravizados.

Filha de família multicolor. $\mathrm{Na}$ certidão de nascimento carimbada como branca, no sobrenome descendente de italianos, mas 'e o cabelo desta menina, meu deus'? Os pelos da cabeça eternamente manuseados, trancados - operação dolorida. Amarrar, prender bem apertado. O cabelo o que não podia aparecer. Tragédia privada. A aparição em público sempre calculada. E mesmo assim: 'nossa! nasceu até clarinha, mas o cabelo tão ruinzinho!

Em meu caso em específico, o cabelo precipitou certo tom de descontinuidade, operando como disparador do que chamaria de certa experiência negra. Sentidos que precediam e invadiam e, que durante certo tempo da vida, achei que deles não haveria escapatória possível. Contudo, outros encontros, outros tempos, outras vozes, sons, tons e cheiros foram tornando evidente a falácia destes sentidos já postos, ressoando a possibilidade de outras experiências corporais, de insuspeitos outros mundos em mim.

Assim que, problematizar modos de subjetivação de certa experiência feminina negra coloca-se como desafio; suscitando inquietações vividas ora com perplexidade, ora com sofrimento, ora como geradoras de ação e reflexão. Neste sentido, acompanha estes escritos certa ética do estranhamento; uma urgência de quebrar com a naturalidade de sentidos já prontos que tentam dizer a verdade acerca dos corpos, em um processo de questionamento da homogeneidade e da coerência das formas que aí estão no mundo (Coimbra e Nascimento, 2004:1). Isto implica na criação de dispositivos que permitam visibilizar determinados jogos de poder atuantes na produção de corpos, criando assim um campo de composição de experiências corporais que operem na tentativa de abrir espaço, de dar passagem à invenção de outros possíveis quando dos movimentos da vida. 
Os cabelos?!... ora 'inimigo a se domar', como dizem algumas propagandas de shampoo, ora catalisador de experimentações que descabelam, criam. Trançam-se aqui os nós, portanto, da afirmação de possibilidades de resistência em ato, feita diretamente de carne, pele e pelos, em detrimento de dispositivos que operam dizendo quem somos ou quem devemos ser, em um processo de abertura de sentidos.

Permeando de perto os tracejados desta composição têm-se, pois, a problemática da produção de uma vida ético-estético-política que agencie estratégias na criação de liberdades possíveis, em uma sempre aberta possibilidade de experimentação de tornar-se outra. Liberdade aqui tomada não como abstração ou ideal a ser atingido, mas justamente como exercício cotidiano e concreto; experiência da transformação, da novidade, da transgressão de limites, do ir mais além daquilo que se é na sempre invenção de modos de vida (Larrosa, 2000:332).

\section{2- ENTRELAÇAMENTOS}

Partir-se-á inicialmente do rastreamento de algumas linhas de forças, no caso aqui gênero e raça, que vão participar da constituição de políticas de subjetivação que atravessam vidas femininas negras. $\mathrm{O}$ encontro destes marcadores, que por sinal carregam histórias bem diversas, não funciona como simples soma matemática que opera pela mera adição de elementos e sim, muito mais ao modo de catalisadores químicos que nos seus disparos, arranjam e desarranjam questões, alterando a cada movimento as suas propriedades iniciais.

Hierarquias sobrepostas a hierarquias. Enquanto raça vai dizer de um atravessamento hierárquico entre grupos constituídos como heterogêneos, a questão de gênero vai cruzar os atravessamentos no interior de cada um destes grupos (Guillaumin, 1994:230). Em contextos estratificados por gênero e raça, o gênero vai funcionar também como categoria racial e a raça como categoria de gênero (Harding, 1986:18).

Corrêa (1996:45) sugere um continuum nas hierarquizações: como se houvesse Masculino e masculino, Feminina e feminina, e assim, 'tanto o negro quanto a negra teriam que 'branquear' para aproximar-se do pólo idealizado (M e F) em cada um deles”. A distinção racial vai complexificar e mostrar que as aparentes categorias binárias de gênero não se resumem a seus opostos, uma vez que se conectam a estas determinados sentidos, que vão produzir intervalos e rachaduras nestas classificações, de modo a operar na produção de novos arranjos. Por sua vez, o rearranjo destas categorizações e suas misturas vai ainda funcionar como modo de hierarquização já que, mesmo em suas variações, vão continuar a produzir identidades valorativas para os corpos. 
Nesta perspectiva, o que se quer afirmar é que no processo de imposição de identidades aos corpos, elencam-se diferentes gradações que tentam cobrir e reconhecer o maior número de diversificações possíveis em seu interior, para que de acordo com as circunstâncias, as pessoas nelas possam vir a se reconhecer. Categorias que forjam em meio a outras, na tentativa de delimitar e controlar experiências e espaços possíveis para os corpos.

No caso brasileiro, mais especificamente, a partir de uma ordem gênero-racial já naturalizada, operam-se ativa e cotidianamente uma série de enquadramentos sociais dirigidos aos corpos femininos negros; constrangimentos que funcionam na tentativa de traçar estereótipos quando da constituição destes corpos. A repetição de determinados modelos de identidade visa acomodar a contradição incorporada nos corpos femininos negros, por meio de sua "inscrição em regimes locais de subalternização" (Pinho, 2004:20-4). E através da apresentação destes como "alegorias da verdade", acabam por tornar mais aceitáveis as sujeições sociais a que remetem (Pinho, 2007:20-4). Por outro ângulo, destaque-se que estas diferentes formatações identitárias constituíram-se em um limiar entre "acomodação, conflito, resistência e imposição da opressão" (Pinho, 2004:20-4).

Uma das singularidades brasileiras é o caráter silencioso destes constrangimentos que, geralmente, se camuflam em cima de "uma suposta garantia de universalidade e da igualdade das leis", lançando "para o terreno do privado o jogo da discriminação", e fazendo da "desigualdade uma etiqueta internalizada e da discriminação um espaço não formalizado”. (Schwarcz, 2004:2-9). Assim é que no país coexistem realidades distintas: de um lado o consumo e a propaganda de terra mestiça (e que beira o exotismo) em suas crenças e hábitos, e de outro, um racismo arraigado na intimidade e que (re)produz hierarquias em sua invisibilidade operante (Schwarcz, 2004:68). Neste sentido, o corpo feminino negro aglutina uma série de tensões que dizem de modos de exclusão e segregação dos corpos na vida brasileira.

Estrategicamente, contudo, o desafio talvez seja trabalhar raça e gênero não centrando as análises em suas dimensões já instituídas, de fechamento de sentidos, em uma mera descrição das diferenças que estão já aí postas. E sim, muito mais, utilizar estas categorias como ferramentas, tentando apostar, assim, em sua potência de visibilizar específicos jogos de poder que participam da constituição de corpos.

Quanto ao termo raça, seja embasado em pressupostos biológicos, culturais ou estéticos, este vai funcionar na tentativa de instituir e essencializar determinadas verdades acerca de determinados segmentos da população, servindo, muitas das vezes, como critério para diferenciar grupos sociais subordinados (Parente, 2000:6). Assim, pode ser utilizado como termo imediatamente político, na medida em que permite rastrear procedimentos e práticas de raça usadas 
na legitimação de determinadas interpretações atuantes na constituição e gestão de corpos (Pinho, 2007:19-21).

Quanto ao termo gênero, este é aqui tomado na perspectiva dos estudos feministas contemporâneos, que procuram justamente operar na abertura de linhas feministas de fuga, na desconstrução do sistema sexo/gênero e na produção de seres nômades que não se conformem às ordenações binárias de sexualidade (Rago 2003:488).

Gênero e raça configuram-se, portanto, como modo de evidenciar a arbitrariedade de certos jogos de poder que participam da determinação de linhas a serem atualizadas pelos corpos, operando na demolição de algumas produções de sentidos identitários que vêm se atualizando como hegemônicos.

\title{
3- A PRODUÇÃO DE CORPOS FEMININOS NEGROS
}

Útero, vagina, pele preta, cabelo crespo que cresce pra cima: mulher negra?

\begin{abstract}
Ao longo dos tempos, os sujeitos vêm sendo indiciados, classificados, ordenados, hierarquizados e definidos pela aparência de seus corpos; a partir de padrões e referências, das normas, valores e ideais da cultura. A cor da pele ou dos cabelos; o formato dos olhos, do nariz ou da boca; a presença de vagina ou pênis; o tamanho das mãos, a redondeza das ancas e dos seios são, sempre, significados culturalmente e é assim que se tornam (ou não) marcas de raça, gênero, de etnia (...). Podem valer mais ou valer menos. (...) Características dos corpos significadas como marcas pela cultura distinguem sujeitos e se constituem em marcas de poder (Louro 2004:75-76).
\end{abstract}

Marcas que, muitas das vezes, funcionam como se a sentença de uma vida, suas alegrias e desventuras estivesse já posta pela combinação aleatória dos genes que constituiriam seu fenótipo. Mas qual seria então a relação entre corpos e os sentidos a eles atribuídos?

Ora, o sentido vai funcionar enquanto referência, dando visibilidade a certas relações dos corpos e produzindo um referente em um recorte a posteriori e em ato. Referente que não é, portanto, um objeto natural (Lobo, 2004:202). Donde se depreende que os corpos vão ser objetivados por diferentes práticas e relações a cada contexto histórico. De modo que não existe nenhuma referência ao corpo que não seja, simultaneamente, uma formação adicional deste mesmo corpo (Butler, 1999:163-164).

A categoria sexo, por exemplo, localizador corporal de uma suposta diferença entre homens e mulheres, opera na demarcação de regiões corporais bem específicas, a saber, vagina e pênis. Pode-se afirmar que esta categoria vai justamente operar como "parte de uma prática regulatória que produz os corpos que governa", isto é, uma espécie de poder produtivo, "poder de produzir demarcar, fazer, circular, diferenciar - os corpos que ela controla” (Butler, 1999: 153-154). Também 
a questão da raça pode ser tomada nesta mesma perspectiva, uma vez que também opera na objetivação de certas características que se elegem em meio a outras como passiveis de demarcação e diferenciação entre corpos. Com a diferença de que, ao invés do aparato genitália-órgãoshormônios, aqui se tem, por exemplo, cor da pele, cabelo, formato nariz-boca como marcadores de poder.

O que se quer frisar aqui é que classificações raciais e de gênero vão incidir no processo de objetivação dos corpos, criando referentes e valores associados a estas referências. "Sentidos que os corpos habitam e que recortam, em determinado momento, certas relações e não outras" (Lobo, 2004:202). Matéria que se faz em ato a cada vez.

Vagina, pele preta e cabelo crespo que cresce para cima, nesta perspectiva, apesar de existirem fisicamente, só servem como referências dentro de uma classificação gênero-racial, como mulher negra, se consideradas como fabricadas por relações produtivas de poder. Tomando, junto com Foucault (2005), uma definição de poder como positividade, um modo de relação das forças na composição de planos de realidade, tem-se então que o poder:

opera sobre o campo de possibilidade onde se inscreve o comportamento de sujeitos ativos; ele incita, induz, desvia, facilita ou torna mais difícil, amplia ou limita, torna mais ou menos provável; no limite, ele coage ou impede absolutamente, mas é sempre uma maneira de agir sobre um ou vários sujeitos ativos, e o quanto eles agem ou são suscetíveis de agir. Uma ação sobre ações (Foucault 1995:243).

Mulher e homem, branca e negra: formas constituídas historicamente que vão operar dando contornos às forças e produzindo sensações e sentidos quando do encontro de corpos. (França, 1998:210). É nesta perspectiva, pois, que se engendram efeitos de normalização que vão atuar justamente na produção de olhos que recortam e classificam, julgam e separam. É o olho do branco para o negro, do magro para o gordo, do saudável para o doente. Olhos que giram em torno de cadeias de referências já dadas, já certas. Processos de normalização como resultado de uma série de operações que instituem e atribuem sentidos a polaridades cujos pólos carregam sempre uma ligação assimétrica entre si (Veiga Neto 2001:8).

Cria-se uma maioria ${ }^{2}$ que no final das contas não é ninguém: o homem branco, saudável, urbano, e... Sucessivas e infindáveis exigências, que só fazem distanciar qualquer pessoa deste

\footnotetext{
2 ["Minoria e maioria não se opõem apenas de uma maneira quantitativa. Maioria implica uma constante, de expressão ou de conteúdo, como um metro padrão em relação ao qual ela é avaliada. Suponhamos que a constante ou metropadrão seja homem-branco-masculino-adulto- habitante das cidades-falante de uma língua padrão-europeuheterossexual qualquer (...). É evidente que “o homem” tem a maioria, mesmo se é menos numeroso que os mosquitos, as crianças, as mulheres, os negros, os camponeses, os homossexuais... etc. É porque ele aparece duas vezes, uma vez na constante, uma vez na variável de onde se extrai a constante. A maioria supõe estado de poder e dominação e não o contrário. Supõe o metro padrão e não o contrário. Pois, a maioria, na medida em que é analiticamente compreendida no padrão abstrato, não é nunca alguém, é sempre Ninguém (...)” (Deleuze e Guattari, 1995:37-8)].
} 
“metro-padrão" (Deleuze e Guattari, 1995:37-8). Máquinas de produção de sentidos que operam individualizando, estabelecendo e valorando fronteiras, em meio a um processo que movimenta signos, dores, prazeres.

Assim que, na disseminação dos chamados processos civilizatórios e seus processos de hierarquização, tal como ocorrido no Brasil, o corpo da mulher negra sintetiza atributos dos quais convém se distanciar e que operam como fator de subjugação: inferior por ser mulher, inferior por ser negra. Sentidos inscritos e extraídos dos traços, pele e pelos. Não é porque se tem uma vagina ou um útero que se é mais sensível, ou que se tem disposição para maternidade. Ou se tem uma sexualidade mais exacerbada porque o tom da pele é preto. Não é porque se tem determinada cor que se samba bem, e nem é natural a divisão entre cabelos bons e ruins. Se analisadas em sua arbitrariedade, estas classificações histórica e profundamente enraizadas no cotidiano brasileiro, soariam tão descabidas quanto se fosse senso comum afirmar que as pessoas que têm olhos verdes são mais propensas à loucura que as pessoas que tem olhos pretos.

Neste sentido, coloca-se como quase sempre necessária uma constante negociação com formas de manipulação e assédio em torno de elementos que constituem o corpo feminino negro. O que, de certo modo, vai apontar para outros processos que se desdobram desde o interior destes assédios: o fato de que a reiteração destas práticas seja necessária é sinal de que estes processos de objetivação, nunca se fecham por completo, os corpos nunca se conformam completamente às normas as quais os processos de objetivação os circunscrevem.

Demonstra-se, neste movimento, o caráter fictício e construído dos sentidos que atravessam corpos femininos negros: práticas contingentes e precisas que atuam na produção de modos de existência. O que há de se considerar, portanto, não é a busca por uma naturalidade essencial dos corpos, mas sim problematizar, a cada momento, os efeitos que certas construções produzem. Feixes de possíveis partilhados, vividos e apropriados de maneira singular a cada momento da vida. Corpos femininos negros que por ora cedem a reiterações identitárias e que por outras forjam modalidades de resistência, de modo a fazer escapar outras invenções de si mesmos.

Assim que procurar-se-á doravante espreitar maneiras pelas quais algumas existências femininas negras na construção do presente, ultrapassam e recriam sentidos atrelados a seus corpos de modo a engendrar modos inéditos de existência. Trata-se de considerar sentidos que se deslocam no compasso de encontros e intensidades, esboçando rudimentos de resistências, de aglomerações, lutas. 
Para tanto, partir-se-á das obras e problematizações sugeridas por fragmentos de experimentações de três mulheres negras: Rosana Paulino, Lírio e Flor ${ }^{3}$. A primeira, uma artista visual, pesquisadora, gravurista, escultora e desenhista paulistana. A segunda, uma estudante universitária também paulistana. E por fim Flor, uma trançadeira moradora de um morro no Rio de Janeiro. Serão utilizados trechos da tese de doutorado de Paulino (2011), bem como excertos ${ }^{4}$ de um diário de bordo $^{5}$ com registros dos encontros tidos com Lírio e Flor- as datas serão indicadas em cada caso.

\section{4- TRANSMUTAÇÕES}

"A mulher negra... Qualquer coisa que a gente faça é mal vista. Vamos falar do cabelo: se você alisa o movimento negro fala que você tá negando sua raça. É só cabelo, posso fazer o que quero com ele. É que nem pintar unha. No meu ponto de vista você não tá negando a raça. Agora se você aparece com o cabelo black, todo estiloso, super bonito, as pessoas logo vêm: 'Cabelo pixaim, tem preguiça de pentear. Porque não alisa?' Se eu quiser andar com cabelo crespo ando e pronto. Vai falar que não quero pentear e daí? Da vontade de deixar metade liso e metade crespo. Falar com umas pessoas de um lado e com as outras do outro lado. Assim ninguém reclama”.

(Lírio, São Paulo, Inverno, Diário de bordo).

Os corpos sempre excedem as marcações que os constrangem, ultrapassando formas que tentam limitá-lo a este ou àquele modelo. A questão que aqui se levanta não é a da produção de guetos demarcadores de sentidos que se pretendam mais ou menos verdadeiros para os corpos, mas sim a da produção de uma política que conjugue e conecte elementos de minoria, de maneira a inventar, neste processo, uma política feminina intensiva (Deleuze e Guattari, 1995: 51). A referência a uma política intensiva afirma, nesta perspectiva, a abertura de uma certa afectabilidade que permita a cada vez a inauguração de outros modos de sentir e perceber o próprio corpo e o

\footnotetext{
${ }^{3}$ [Os nomes destas mulheres foram aqui substituídos por nomes de flores; alusão a potência de brotejar e desabrochar destas vidas].

${ }^{4}[$ Versões modificadas extraídas de Longo (2011)].

5 [Ferramenta do âmbito da análise institucional, que permite acompanhar os processos do pesquisar, evidenciando o "fora texto". Nas palavras de Lourau (1993:37) o fora texto pode ser tomado como "escrita quase obscena, violadora da neutralidade". O que se tenta evidenciar é o quanto esta neutralidade é impossível, uma vez que, de um modo ou de outro, sempre se está imersa naquilo que se pesquisa].
} 
mundo. É imperativo a demolição de quaisquer sentidos que circunscrevam a experiência feminina negra de modo a dar passagem a modos singulares de produção de existências.

É esta a aposta de Rosana Paulino:

(...) faz parte do meu fazer artístico apropriar-me de objetos do cotidiano, ou de elementos pouco valorizados para produzir meus trabalhos. Objetos banais, sem importância. Utilizar-me de objetos do domínio quase que exclusivo das mulheres. Utilizar-me de tecidos e linhas. Linhas que modificam o sentido, costurando novos significados, transformando um objeto banal ridículo alterando-o tornando-o um elemento de violência, de repressão. O fio que torce, puxa, modifica o formato do rosto, produzindo bocas que não gritam, dando nós na garganta. Olhos costurados, fechados para o mundo e, principalmente, para a sua condição de mundo. Apropriar-me do que é recusado e malvisto. Cabelos. Cabelo "ruim", "pixaim", "duro". Cabelo que dá nó. Cabelos longe da maciez da seda, longe do brilho dos comerciais de shampoo. Cabelos de negra. Cabelos vistos aqui como elementos classificatórios, que distinguem o bom e o ruim, o bonito e o feio (Paulino, 2011:89).

Ao apropriar-se do presente e de seus elementos, Paulino acaba por dar mobilidade às condições históricas e identitárias que atravessam os modos de constituição de corpos femininos negros. A experiência feminina e negra desloca-se de uma mera constatação dos atributos objetivados via hierarquizações que os desqualificam, emergindo como um plano de intensidade, plano de forças e virtualidades de onde emergirão materiais na produção de obras de existências.

Destaque-se Sem Título (para as Três Graças) (1998) ${ }^{6}$, trabalho de Paulino irônica e criticamente endereçado às três Graças, deusas da mitologia grega representadas por muitos artistas renascentistas como símbolos da harmonia e da beleza. Na obra, emaranhados de cabelos negros estão colocados sobre bastidores de costura dispostos de modo semelhante entre si, dando a impressão de uma série. Embaixo de cada bastidor, um nome feminino distinto: Alice, Dulce, Helena, Nadir, etc. A exceção é um bastidor colocado mais ao centro, que exibe uma mecha de cabelo negro ao lado de um feixe de cabelo loiro e liso. Ao selecionar e agrupar fios de cabelos, nomes e peças de bordado desvinculando-os de suas funções cotidianas, a obra embaralha o olhar e os sentidos, dando por sua vez um caráter problematizador e provocativo a certa generalização de identidades femininas negras que se processam via cabelo. Rosana, ao mesmo tempo em que faz uma crítica à modelos historicamente arraigados, tece singularmente um plano de expressão de vidas, instaurando e rearranjando blocos de forças intensivas que operam no deslocamento de sensibilidades. Caleidoscópios de elementos que ora aproximam, ora desviam sentidos quando da constituição de vidas femininas negras.

\footnotetext{
${ }^{6}$ [Obra plástica de Rosana Paulino; imagem disponível em http://vivalavulva.wordpress.com/2012/04/08/rosanapaulino].
} 
Na instalação Da memória e das sombras: As amas (2009), também de Rosana Paulino, produzida em uma senzala conservada no subsolo de um casarão colonial no interior de São Paulo, diversas mãos pretas moldadas em couro brotam unidas de sulcos produzidos nas duras paredes do lugar. Delas escorrem fitas de cetim brancas que se derramam até objetos dispostos no chão. Cada um destes objetos, por sua vez, compõe-se de pedaços de vidro, cera, pétalas e recortes de fotografias de partes do corpo. O ato de entrega das mãos, a fita-branca- líquida- leite em sua potência nutritivo-estética, ali escancarados na senzala, deslocam sentidos e fazem consistir outras dimensões destas vidas escravizadas. As mãos de Paulino apropriam-se das memórias da escravatura brasileira, de uma perspectiva que não se contenta em lamentar ou representar uma versão da história, mas sim que cria sensivelmente outros modos de contá-la: amas de leite emergem nesta obra em sua potência concentrada de cuidado, doação, nutrição, embalo, recepção.

\begin{abstract}
Essas amas são integralmente suas mãos, que evocam o trabalho escravo, o serviço e também o afeto, o toque. São receptivas, estão surpreendentemente postas em gesto generoso, oferecendo laços e fios que indicam caminhos e impressões. A dualidade presente na imagem - ao mesmo tempo sombria e acolhedora - instiga a uma revisita dos lugares da memória em nosso tempo. Passamos a um interesse singular por essas estórias apagadas, a perguntar quem foram essas mulheres capazes de doarem-se; vidas que ganham ressignificação poética pela precisão do olhar de Rosana Paulino. Essas obras também não deixam de promover uma problematização sobre a constituição de indivíduos livres, sacudindo a poeira de memórias quase adormecidas, ressignificando a experiência da dor e da submissão e, ao mesmo tempo, trazendo à tona relampejos e instantes belos, mesmo em sua pequenez, diante do poder (Tvardovskas, 2010:92).
\end{abstract}

Sutilmente vão consistindo experiências que transmutam sentidos e memórias; suaves e firmes mãos multiplicando e ampliando enredos. Fragmentos de práticas que simultaneamente repetem e cortam histórias. Vidas femininas negras que a cada vez, a partir de seus fazeres experimentam a criação de outros possíveis.

"Você negra? Ficar bonita, você? Tem que sofrer! Olha lá a beleza... Esquece que você é negra do cabelo fino, tem que chegar no loiro do olho azul" - ironiza Flor, que trabalha fazendo tranças em cabelos há 15 anos.

Uma das maiores questões em seu trabalho é a problematização da dor que está embutida na maioria das intervenções estéticas que as mulheres realizam. Conta que a mulher está acostumada a sofrer quando se trata de beleza. A mulher negra mais ainda. Especialmente no que se refere a cabelos.

"São pequenas e muitas coisas que a vida vai te impondo, que você acha que é necessário. A mulher carrega muitos fardos. O quanto sofro sem perceber que estou sofrendo? É caminho da opressão todo dia. Você tem que ser sempre outro pra ser você mesmo. Que 
mundo é este? Você tá construindo? Ou já existe e você não viu? Quando tempo isto no ser humano? Você tem que ser igual a uma coisa? Mas porque eu tenho que sentir dor pra ficar bonita? Porque todo mundo que é igual a mim tem que sentir dor pra ficar bonita? Nossas crianças vão continuar repetindo isto? Quis começar a entender”- afirma.

Conta que quando tinha quinze anos fazia trança com uma mulher que "puxava o cabelo pra caramba", "era muita dor e ela dizia que tinha que puxar o cabelo pra crescer". Ao que Trançadeira Flor hoje retruca: "quanto mais puxa, menos ele cresce. Mais ele quebra e pode fechar o poro". "Mesmo a pessoa que trança: se ela puxa é porque ela mesma não está relaxada, ela tá tensa e trabalhando com a mão errada, podendo ficar com tendinite".

Frisa que toda uma gama de acessórios dirigidos ao "tratamento" do corpo da mulher negra, passa pela questão da dor. Desde os ácidos alisantes de cabelo disponíveis no mercado até mesmos penteados que se intitulam como "afros" costumam ser presos, puxados, doloridos: "Eu tava pegando tudo de fora e colocando pra dentro. Só que não cabia... Que mundo é este que a gente vai chegar”?

E é ai que Flor intervém:

"Fui vendo como fazer pra não doer (ao manipular os cabelos). Fui inventando todo um jeito de trançar sem que a pessoa sentisse dor. Se doía prestava atenção em porque estava doendo. Estimulo quem ta perto a trabalhar o bonito. A pessoa senta na minha cadeira e relaxa. Não é só cabelo entende? É todo um modo de se fazer aquilo. Trata-se muitas das vezes de lá naquela cadeira reconstruirmos a vida...”.

(Flor, Rio de Janeiro, Inverno, Diário de bordo).

Por intermédio de seus fazeres, esta trançadeira ocupa-se a cada vez, não apenas do cabelo, como também das sensações, afectos mobilizados, construção que se faz na relação mãos, cabelos, voz, ouvidos. Flor dirige sua atenção às muitas políticas intensivas que a cada momento constituem corpos, não apenas transmutando seu fazer em prazer, como também empreendendo uma contínua problematização dos modos pelos quais se está dando passagem às afecções que atravessam a composição de vidas atravessadas pelo feminino negro. Ao interferir sobre a questão da dor ao trançar, Flor acaba por desmontar uma série de dispositivos que associam a aparência feminina negra a compulsivas e doloridas práticas de transformação. Voltando sua atenção para os sentidos que se forjam na contingente imanência dos fazeres, acaba por agenciar novas estratégias quando da produção do corpo feminino negro, espreitando neste movimento possíveis produções de liberdades. Trançadeira Flor, nesta perspectiva, em seu minúsculo deslocamento acaba por inventar modos singulares de relação para com o corpo feminino negro. 
A experiência de minoria feminina e negra tão atrelada ao corpo, só se faz efetivamente criadora na medida em que faz emergir outra dimensão da vida. Na medida em que faz passar por entre os códigos e verdades, algo que não se deixa e nem se deixará codificar: "fazê-lo passar num novo corpo, inventar um corpo no qual isso possa passar e fluir: um corpo que seria o nosso, o da terra, o do escrito..." (Deleuze, 2011:3-4).

\footnotetext{
"Não adianta, não vai nascer cabelo liso. Você vai carregar isto a vida inteira nas suas costas? Eu não vou carregar, vou é andar junto. Transformar dor em ardor. Ter uma questão já é um caminho. Se você sente um monte de coisas e não está nem aí, fica difícil. Eu vivo mesmo nesta história de tentar usar a verdade ao meu redor. Por mais que doa... É um desafio, este negócio de nunca ser completamente, e ao mesmo tempo você é. Você não é nada, e você é. Saber o que se é, dentro deste nada em que se é tudo".
}

(Flor, Rio de Janeiro, Inverno, Diário de bordo).

Curiosa experiência de transmutação: na medida em que constrangimentos que cerceiam existências femininas negras se processam via desvalorização de atributos do corpo, é também via acolhimento e apropriação de outras dimensões intensivas corporais que se conectam intempestivas linhas de fuga, abertura de outros possíveis. Nas teias forjadas pelo mundo atentar para os encontros que se processam desde um corpo que é poroso, composto na heterogeneidade, no sempre atravessamento de membranas, fluidos e velocidades. Aspectos sensíveis do corpo que, abertos a força dos encontros, tornam-se motor para uma relação consigo em que se é causa ativa da própria existência (Ribeiro, 2009: 45).

\footnotetext{
"Meu trabalho como trançadeira é uma forma de dar conta. É minha vida que eu tô pondo neste trabalho. E daí quando eu vi o peso disso, daí eu tenho que ser corrupta ou colocar as minhas verdades. Quando comecei a pensar diferente, andar diferente, as coisas começaram a ficar diferentes”.
}

(Flor, Rio de Janeiro, Inverno, Diário de bordo).

A partir do questionamento e deslocamento das práticas e intensidades que atravessam experimentações femininas e negras, Rosana Paulino e Flor acabam por construírem-se a si mesmas, insinuando inéditos modos de sentir, pensar e existir. Práticas femininas negras imediatamente potentes e criadoras na medida em que se desviam de sentidos instituídos entristecedores impelindo os corpos na inauguração de novos regimes de sensibilidade e afetação. Em meio a fabricação de artes plásticas e tranças, estas vidas femininas negras acabam não apenas por produzirem suas obras, como também por serem produzidas por elas. Vidas femininas e negras 
que, na potência de seus fazeres, selecionam sentidos, em movimentos que simultaneamente desmontam modelos e afirmam outros possíveis para estes corpos. Experiência de acolhimento e transfiguração que se traça no tempo e no espaço em que se ocupa; força curadora extraída do próprio sofrimento (Nietzsche, 2000:7).

Tocaram-me sempre as questões referentes a minha condição de mulher e negra. Olhar no espelho e me localizar em um mundo que muitas vezes se mostra preconceituoso e hostil é um desafio diário. Aceitar as regras impostas por um padrão de beleza ou de comportamento que traz muito de preconceito, velado ou não, ou discutir esses padrões, eis a questão.

(...)

Pensar em minha condição no mundo por intermédio de meu trabalho. Pensar sobre as questões de ser mulher, sobre as questões da minha origem, gravadas na cor da minha pele, na forma dos meus cabelos. Gritar, mesmo que por outras bocas estampadas no tecido ou outros nomes na parede. Este tem sido meu fazer, meu desafio, minha busca. (Rosana Paulino, 2011:88)

Obras que se constituem em meio ao acolhimento e apropriação de intensidades que atravessam corpos. Arranjos que investem nos detalhes, nos afectos, na potência de produzir e contaminar de mãos e fios, de modo a forjar outros modos de experimentação de vidas femininas negras. Práticas que transfiguram facetas de dor e ressentimento, inaugurando modos minoritários de existência. Vidas que se trançam em rede com as forças mundanas, movidas pelo desassossego da sempre efetivação de novos sentidos quando da produção da própria existência.

\section{6- DAS INCONCLUSAS OBRAS DE VIDAS}

Normativas de controle que se sustentam no corpo configuram-se como uma das principais estratégias biopolíticas do contemporâneo. São postos a funcionar, constantemente e pelas mais diversas redes, processos que cavam uma interioridade nos corpos, modulando vidas femininas negras através do ordenamento, regulação e valoração dos atributos corporais externos. Estratégias de constrangimento da vida que se exercem por entre expectativas corporais reificadas nas mais diversas instâncias, gestos e práticas cotidianas, de maneira a limitar possibilidades e modos de existência femininos negros.

A questão que se levanta não é apenas indicar a urgente tarefa de demolição dos sentidos hegemônicos que se atrelam aos corpos femininos negros, mas também a de evidenciar que esta desconstrução remete ao questionamento de certa lógica social que atravessa todos os corpos, regulando a produção de feminilidades e masculinidades negras e brancas. Não se trata aqui, portanto, da reivindicação por inclusão na mesma lógica social que categoriza estes corpos, mas justamente da sustentação e afirmação da potência de diferenciação que estes corpos sugerem, de modo que seja possível, quem sabe, a desestabilização desta mesma lógica. 
$\mathrm{Na}$ medida em que se desvia do padrão hegemônico masculino branco, o corpo feminino negro pode vir a sugerir outros arranjos possíveis quando da construção de corpos no contemporâneo. Arranjos que invistam justamente na criação do presente e dos modos de habitálo. Trata-se de um necessário deslocamento das linhas de força que operam na criação de modelos para os corpos; linhas que operam demarcando fronteiras e valorando existências de maneira hierárquica. É imperativa a construção de novos modos de relacionar-se com o próprio corpo, com a história, com a vida, problematizando e interferindo nas práticas e relações que produzem os corpos enquanto tais. Desdobra-se, com isto, a forçosa tarefa de desconstrução das classificações valorativas de raça e gênero nos processos e embates cotidianos, de modo a dar passagem ao acolhimento da sempre renovada necessidade de invenção de conexões com as forças do mundo. Afinal trata-se de, em um chamado de inspiração foucaultiana, fazer da própria a vida uma obra de arte:

\footnotetext{
O que me surpreende é o fato de que, em nossa sociedade, a arte tenha se transformado em algo relacionado apenas a objetos e não a indivíduos ou à vida; que a arte seja algo especializado ou feita por especialistas que são artistas. Entretanto, não poderia a vida de todos se transformar numa obra de arte? Porque deveria uma lâmpada ou uma casa ser um objeto de arte, e não a nossa vida? (Foucault, 1995a: 261)
}

Por entre estes escritos vagam mãos e vozes que questionam, tecem, cuidam e trançam. Delicadas e firmes artesanias, em desassossegos críticos e criadores, sugerindo modos de construção de vidas que escapam das categorizações que constrangem corpos. Estilhaços de práticas femininas negras operando na tentativa de quebra de sentidos identitários entristecedores de modo a liberar forças de ação e transmutação. Ardorosos desabrochares de obras de existência convocando outros mundos possíveis.

\section{REFERÊNCIAS}

BUTLER, J. Corpos que pesam: sobre os limites discursivos do sexo. Em: Louro G. L. Corpo Educado: pedagogias da sexualidade. Belo Horizonte: Autêntica, 1999.

COIMBRA, C. M. B. e NASCIMENTO, M.L. Sobreimplicação: práticas de esvaziamento político? 2004- Universidade Federal Fluminense Niterói/RJ. Disponível em: www.slab.uff.com.br. Acesso em outubro de 2005. 116.

CORRÊA, M. Sobre a invenção da mulata. Em Cadernos Pagu, n. 6-7, Unicamp, Campinas, 1996. 
DELEUZE, G. \& GUATTARI, F. Mil platôs. - Capitalismo e esquizofrenia, vol. 2. São Paulo: Ed. 34, 1995.

DELEUZE, G. Pensamento nômade, Capturado em http://intermidias.blogspot.com/2011/10/pensamento-nomade-por-gilles-deleuze.html. Acesso em 23/10/2011.

FOUCAULT, M. O sujeito e o poder. Em: Dreyfus e Rabinow. Michel Foucault, uma trajetória filosófica. Rio de Janeiro: Forense, 1995.

FOUCAULT, Michael. Sobre a genealogia da ética- uma revisão de trabalho. Entrevista a Hubert Dreyfus e Paul Rabinow. Em Rabinow e Dreyfus. Michel Foucault: uma trajetória filosófica. Para além do estruturalismo e da hermenêutica. Rio de Janeiro, Forense Universitária, 1995a.

FOUCAULT, M. História da sexualidade v. I: a vontade de saber. Rio de Janeiro, Ed Graal, 2005.

FRANÇA, S.A.M. Diferença e preconceito: a efetividade da norma. Em Aquino, J. Diferença e preconceito na escola: alternativas teóricas e práticas. São Paulo, Summus, 1998.

GUILLAUMIN. Enquanto tivermos mulheres para nos darem filhos: A respeito da raça e do sexo. Em Estudos Feministas, Santa Catarina, número especial, v 2, 2 semestre/1994.

HARDING,S. The Science question in feminism. Milton Keynes, Open University Press,1986.

LARROSA, J. A libertação da liberdade. Em Portocarrero,V, Branco,G.(orgs) Retratos de Foucault, Rio de Janeiro, Ed. Nau, 2000.

LOBO, L. Pragmática e subjetivação por uma ética impiedosa do acontecimento. Em Psicologia em Estudo, Maringá, v 9, n 2, mai/ago 2004.

LONGO, N.L. Políticas do corpo: subjetividades femininas negras. Dissertação de Mestrado. Programa de Pós-Graduação em Psicologia. Universidade Federal Fluminense, 2011.

LOURAU, R. Análise Institucional e práticas de pesquisa. Rio de Janeiro. Ed UERJ, 1993.

LOURO, G. L. Um corpo estranho. Belo Horizonte: Autêntica 2004. 
NIETZSCHE, F. Crepúsculo dos ídolos ou como filosofar com o martelo. Rio de Janeiro: Relume Dumará, 2000.

PARENTE, Regina Moçambique de Osório: exílio de um reino negro na diáspora. Porto Alegre. Dissertação (Mestrado em Educação) - Programa de pós graduação em Educação. UFRS, Universidade Federal do Rio Grande do Sul, 2000.

PAULINO, R. Imagens de sombras. Tese de doutorado. São Paulo, Escola de Comunicação e Artes da Universidade de São Paulo, 2011.

PINHO, O. Efeito do sexo: políticas de raça, gênero e miscigenação. Em Cadernos Pagu, n. 23, Campinas, 2004.

PINHO, O. A produção da raça, teoria e prática: a gestão do corpo e do conhecimento. Em Rezende, Maria A. (org.) Educação, cultura e literatura afro-brasileira. Rio de Janeiro: Quart, UERJ, Centro Negro, 2007.

RAGO, M. Por uma educação libertária: o gênero na nova escola. Em: Barbosa, R. Formação de educadores: Desafios e perspectivas. São Paulo. Ed. da Universidade Estadual Paulista, 2003.

RIBEIRO, R. Sensorial do corpo: via régia ao inconsciente. Dissertação de Mestrado. Programa de Pós- Graduação em Psicologia. Universidade Federal Fluminense, 2009.

SANTOS, J. T. O negro no espelho: imagens e discursos nos salões de beleza étnicos. Em Estudos Afro-asiáticos, n.38, dez 2000.

SCHWARCZ, L. M. Nem preto, nem branco, muito pelo contrário: cor e raça e na intimidade. Em Schwarcz, L. M. História da vida privada no Brasil, v. 4. São Paulo. Companhia das Letras, 2004.

TVARDOVSKAS, L. S. Modos de viver artista: Ana Miguel, Rosana Paulino e Cristina Salgado. Em Rago, M. Dossiê Estéticas da Existência. Revista Aulas, n 7, Unicamp, Campinas, 2010.

VEIGA-NETO, A. Incluir para saber. Saber para excluir. Em Pro-posições, v12,n 2-3,jul-nov, 2001. 